\title{
Feasibility Design Study of High-Performance, High-Power-Density Propulsion Motor for Middle-Range Electric Aircraft
}

\author{
Ahmed Hebala ${ }^{1 *}$, Stefano Nuzzo ${ }^{1,2}$, Giuseppe Volpe ${ }^{3}$, Peter H. Connor ${ }^{1}$, Paolo Giangrande ${ }^{1}$, Chris Gerada ${ }^{1}$, \\ Michael Galea ${ }^{1,4}$ \\ ${ }^{1}$ Power Electronics, Machines and Control (PEMC), University of Nottingham, United Kingdom \\ ${ }^{2}$ Department of Engineering Enzo Ferrari within Università degli Studi di Modena e Reggio Emilia, Italy \\ ${ }^{3}$ Motor Design Ltd. Wrexham, United Kingdom \\ ${ }^{4}$ Key Laboratory of More Electric Aircraft Technology of Zhejiang Province, University of Nottingham, Ningbo, China \\ Email:ahmed.hebala@nottingham.ac.uk
}

\begin{abstract}
$\square$ Abstract - This paper deals with the design of a high powerdensity, high efficiency and low torque ripple propulsion motor for electric aircraft. The proposed design procedure resulted in a high-performance propulsion motor intended for a direct-drive solution on an 8-12 passenger commercial aircraft with a range up to $\mathbf{1 0 0 0}$ miles. The electromagnetic design is firstly addressed and then the thermal management is discussed. A set of design development steps are investigated and validated through finiteelement software, involving studies for the optimal selection of the of air gap diameter and the slot/pole combination, followed by improving the efficiency by suitable material selection and methods for losses mitigation. Finally, in order to prove the enhancement of power density and efficiency through this feasibility design study, the designed propulsion motor performance is compared to the state-of-the-art motors of similar direct-drive aircraft propulsion systems.
\end{abstract}

Index Terms-- All Electric Aircraft (AEA), Aircraft propulsion, Electrification, Finite Element Analysis (FEA), Machine design, More Electric Aircraft (MEA), Permanent Magnet Synchronous Motor (PMSM).

\section{INTRODUCTION}

$\mathrm{T}$ HE electrification of aircraft propulsion is a complex process and requires significant developments in current technologies. It has been set that the road map for an AllElectric Aircraft (AEA) may reasonably be achieved by steps, thus comes the terminology More Electric Aircraft (MEA) [1][3]. The main goals are reducing the emission and noise, which shall be mainly achieved by increasing aerodynamic and propulsion system efficiencies [4], [5]. It is perceived that an AEA has been already operated such as the application of drones and unmanned aircraft [6]. However, moving this success to larger commercial aircraft is not a simple task [7], [8], although aircraft such as B787 is highly considered in the MEA initiatives, but not regarding its propulsion power. The current focus right now, as the possible stepping stone, is on taxi-like applications and middle-mile (up to 1000 miles) flights for aircraft accommodating 2-12 passengers [9], [10]. The propulsion power for such applications ranges from few to hundreds of kilowatts. There are some other ambitious projects such as E-Fan and Zunum Aero where the aim is to partly or

This work is funded by the INNOVATIVE doctoral programme. The INNOVATIVE programme is partially funded by the Marie Curie Initial fully electrify the propulsion of commercially-sized passenger aircraft [11], [12].

Electrical machines with a power range higher than 100 $\mathrm{kW}$ are mainly utilised in platforms such as a 4-seats or even smaller aircraft, as well as in large commercial aircrafts such as the Honeywell machine [13]. On the other hand, electrical machines in the power range of $10-100 \mathrm{~kW}$ are usually used in the case of smaller planes [6]. For Unmanned Aerial Vehicles (UAVs) and remote-controlled small planes, machines rated up to $10 \mathrm{~kW}$ are dominantly used [6].

The scope of this paper is to work on designing a propulsion motor (ProMo) for the middle-mile application where the propulsion power is in the $500-700 \mathrm{~kW}$ range. Focus is given to the electromagnetic (EM) and thermal designs of the ProMo meant for a direct drive configuration. The proposed design strategy starts from a motor designed for short-duty traction application, operated as a direct drive for aircraft electric taxiing, known as Green Taxiing (GT) [14]. Then, this GT machine that is exceptional in torque density $(42 \mathrm{Nm} / \mathrm{kg})$ is used as a reference motor to transform it into a superior power density motor through a series of modifications.

In terms of paper content, the main features and design boundaries of the proposed ProMo design are discussed in Section II. The detailed development of the ProMo design is given in Section III, while in Section IV the thermal management and the final design of the ProMo are presented. The performance and specifications of the designed machine are finally compared to commercially available solutions such as the MagniX-500 and Siemens top-performing prolusion motors [10], [15], thus proving that the proposed design is efficient and has a very competitive power density.

\section{REFERENCE MACHINE AND APPLICATION REQUIREMENTS}

This section covers a description of the GT motor used as the starting technology. The main concept is to transform a hightorque density motor into a high-power density motor. The nature and conditions of operation provide an outlook on how the final design should be. This section introduces the main application requirements and design boundaries for the targeted ProMo.

Training Networks (ITN) action (project number 665468) and partially by the Institute for Aerospace Technology (IAT) at the University of Nottingham. 


\section{A. Description of the reference GT motor}

The main features of the reference machine (i.e. the GT motor, shown in Fig. 1) can be summarized as follows. In order to achieve high torque density, advanced materials, such as Cobalt Iron for the stator core laminations and Samarium Cobalt PMs, were chosen. Subsequently, the stator can tolerate very high magnetic saturation limits, while the PM material provides outstanding performance even at high operating temperatures. The coils are wound so to achieve a concentrated winding, utilizing a double star winding configuration to guarantee a fault-tolerant design. The outer rotor design is employed, with the rotor core made of a solid stainless-steel of the SS-416 grad. The PMs are arranged in a five-stage Halbach array [3]. Therefore, it was possible to get a higher flux density at the air gap, enhancing the torque capability. Nevertheless, Halbach adds manufacturing complexity and increases the total cost. The GT motor incorporated a forced-air cooling system to the stator housing fins. The rest of the GT main characteristics are summarized in Table I.

\section{B. Requirements and boundaries}

The main performance requirements for the new ProMo are summarized as follows:
○ Active Power density $>5 \mathrm{~kW} / \mathrm{kg}$.
- Efficiency $>97 \%$.
○ Torque ripple $<5 \%$.
- Continuous power rating $\geq 560 \mathrm{~kW}$.
- Continuous operating speed $2000 \mathrm{rpm}$

The initial GT motor geometry is used as a starting point for the ProMo design procedure, meaning that the same geometrical constraints have been set. The same core and PMs materials, as well as the PMs arrangement, are initially chosen The DC link voltage is $540 \mathrm{~V}$ equivalent to $345 \mathrm{~V}$ peak phase voltage when using a six-step $180^{\circ}$ modulation [16].

\section{PROMo DEVELOPMENT DETAILS}

The geometries preliminarily obtained via the analytical findings are simulated via 2D finite-element (FE) analysis. The first step in the design process is optimizing the air gap diameter for the ProMo as in the following subsection.

\section{A. Split Ratio Optimization}

The propulsion power and power density requirements, as well as the continuous operation nature of the application, push the design into a liquid cooling one. Henceforth, assuming a liquid cooling configuration, an initial limit for the current density at $\mathrm{Jpk}=15 \mathrm{~A} / \mathrm{mm}^{2}$ has been selected from this point onward [18], [19]. The GT motor has been optimised for an outer rotor topology which is suitable for a traction application. Yet, for aircraft propulsion, it is more convenient to implement an inner rotor configuration [6]. Consequently, to find the optimum geometry for an inner rotor configuration, a study on optimising the air gap diameter is performed by changing the split ratio (SR) of the motor for the 36 slots, 42 poles configuration. The motor outer diameter, axial length, PM thickness and air-gap width are kept unaltered. The remaining features are ranged in the intervals listed below:

- Varying the SR from 0.85 to 0.6 , where the SR is defined as the ratio of the stator outer diameter to the air gap diameter from the stator side.
TABLE I

GT MAIN FEATURES

\begin{tabular}{|c|c|}
\hline Parameter & Value \\
\hline Peak $_{\text {avg }}(\mathrm{kNm})$ & 7 \\
\hline Rated speed $(\mathrm{rpm})$ & 100 \\
\hline Peak power $(\mathrm{kW})$ & 60 \\
\hline Efficiency at peak power $(\%)$ & 69 \\
\hline Active parts weight $(\mathrm{kg})$ & 108 \\
\hline Peak torque density $(\mathrm{Nm} / \mathrm{kg})$ & 65 \\
\hline Peak power density $(\mathrm{kW} / \mathrm{kg})$ & 0.56 \\
\hline Slots/Poles & $36 / 42$ \\
\hline Stack length $(\mathbf{m m})$ & $\mathbf{1 5 1}$ \\
\hline Outer diameter $(\mathbf{m m})$ & $\mathbf{4 6 4}$ \\
\hline PM thickness (mm) & $\mathbf{2 0}$ \\
\hline Air gap radial thickness (mm) & $\mathbf{2}$ \\
\hline Thermal class & $\mathrm{H} / 180{ }^{\circ} \mathrm{C}$ \\
\hline
\end{tabular}

TABLE II

SELECTED Motor From SPLIT RATIO Optimization STUdY

\begin{tabular}{|c|c|}
\hline Parameter & Value \\
\hline No-Load phase voltage (V) & 212 \\
\hline Peak current $(\mathbf{A})$ & 1000 \\
\hline Peak current density $\left(\mathbf{A} / \mathbf{m m}^{\mathbf{2}}\right)$ & 14.4 \\
\hline Full-Load phase voltage $(\mathbf{V})$ & 270 \\
\hline Continuous Average Torque (Nm) & 2944 \\
\hline Power density (kW/kg) & 7.5 \\
\hline Number of Turns per coil & 3 \\
\hline
\end{tabular}

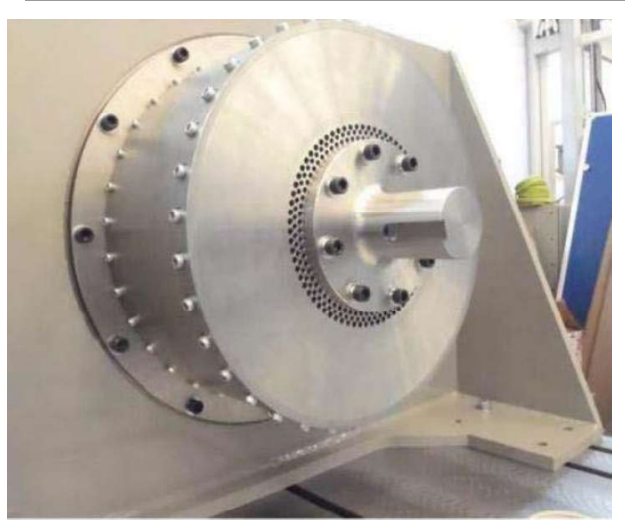

Fig. 1. The GT motor [17].

- Varying the tooth width to slot width ratio from 0.8 to 0.2 , where the slot teeth ratio is defined in this context as the ratio between the teeth width and the slot arc length measured at the teeth tip.

- Maintaining a peak current density of $15 \mathrm{~A} / \mathrm{mm} 2$ and a maximum of $2.2 \mathrm{~T}$ flux density within the stator.

\section{1) Studied configurations}

An EM FE model has been built for all of the possible combinations of SR and tooth width ratio. The main target for this step is to optimize the machine air gap diameter to achieve the highest power density as well as maximising the efficiency (higher than 97\%).

\section{2) Selected configurations}

The stator inner dimensions have been changed as mentioned before, with a total of more than 20 different designs. The results are summarized in Fig. 2, where machines with a SRs of 0.8 and 0.85 seem the best-performing ones in terms of power density. Nevertheless, the efficiency of all designs rarely exceeds $96 \%$. The most promising design in both power density and efficiency is that featuring a SR of 0.8 , and a teeth width ratio of 0.4 . This motor has an air gap diameter of $360 \mathrm{~mm}$, which will be the starting point for the next steps. The flux-line and flux density maps of this motor are shown in Fig. 3. The selected motor's performance is summarized in Table II. The 


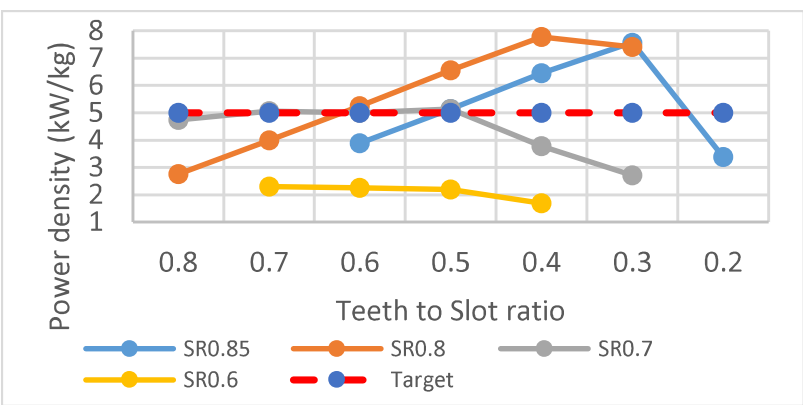

(a)

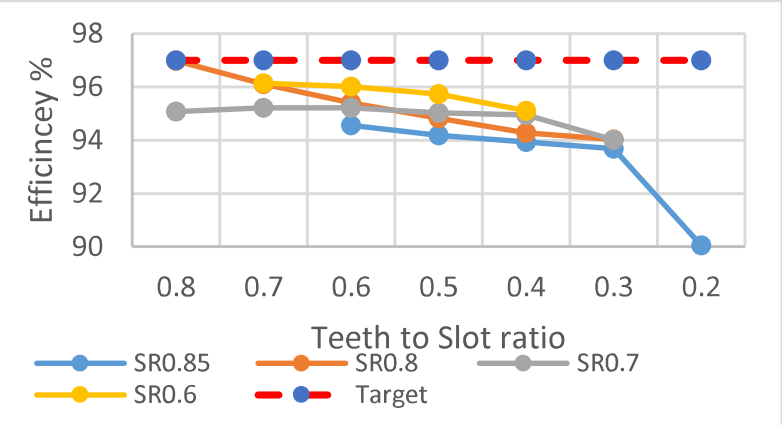

(b)

Fig. 2. Split ratio optimization (a) Power density for the designed motors,

PM losses are very high, i.e. $30 \mathrm{~kW}$ at $700 \mathrm{~Hz}(2000 \mathrm{rpm})$ and with 42 poles. Therefore, it is recommended to optimize the motor number of poles, i.e. the fundamental frequency, which leads to the next step.

\section{B. Slot/Pole Combination}

The preliminary configuration of 36 slots and 42 poles had some challenges, specifically the phase current (Table II), and the PM losses. Hence, another slot/pole combination with a lower number of poles is considered. Several combinations are proposed, then possibly a more suitable combination may be nominated. The selected topologies are listed in Table III, showing the main features of each one. Design fixed variables for the slot/pole combination are:

- PM magnetization, weight and size.

- Air gap diameter at the stator side equals to $360 \mathrm{~mm}$, which has been concluded from the previous step.

- A single 3-phase winding.

There are several promising combinations as the results of Fig. 4 demonstrate, such as the $36 \mathrm{~S} / 30 \mathrm{P}, 36 \mathrm{~S} / 42 \mathrm{P}, 48 \mathrm{~S} / 16 \mathrm{P}$, and $27 \mathrm{~S} / 24 \mathrm{P}$ (where "S" stands for "slots" and "P" for poles). Yet, as the losses breakdown shows in Fig. 5, there are some concerns for all these designs such as copper losses to manage, rotor and PM losses to reduce, very high phase currents, and large turn cross-section area. Based on these considerations, these nominated configurations are subjected to further studies by following the next steps.

\section{Rotor Material}

Although the main contribution of losses comes from the PMs, the rotor core losses are also considerably high. The rotor core losses may not decrease the efficiency by much but could prove to be difficult to dissipate. Therefore, before embarking on reducing the PM losses, the rotor losses are tackled first, simply be implementing laminations instead of a solid core. The GT fundamental's frequency is $35 \mathrm{~Hz}$; subsequently, it exhibits very low eddy current losses through its SS-416 solid rotor. Nevertheless, at higher frequencies due to higher operating
TABLE III

SLOT/POLE COMBINATIONS UNDERSTUDY

\begin{tabular}{|c|c|c|c|c|c|}
\hline Poles & Slots & $\begin{array}{c}\text { Wind. } \\
\text { Layers }\end{array}$ & $\begin{array}{c}\text { Coil } \\
\text { span } \\
\text { (Slots) }\end{array}$ & $\begin{array}{c}\text { Winding } \\
\text { factor }\end{array}$ & $\begin{array}{c}\text { Freq. } \\
\text { (Hz) }\end{array}$ \\
\hline 6 & $\mathbf{3 6}$ & 2 & 5 & 0.933 & 100 \\
\hline 8 & $\mathbf{3 6}$ & 2 & 4 & 0.945 & 130 \\
\hline 10 & $\mathbf{3 6}$ & 2 & 3 & 0.924 & 150 \\
\hline 12 & $\mathbf{3 6}$ & 2 & 3 & $\mathbf{1}$ & 200 \\
\hline 12 & $\mathbf{3 6}$ & $\mathbf{1}$ & 3 & $\mathbf{1}$ & 200 \\
\hline 30 & $\mathbf{3 6}$ & 2 & 1 & $\mathbf{0 . 9 3 3}$ & 500 \\
\hline 30 & $\mathbf{3 6}$ & $\mathbf{1}$ & 1 & $\mathbf{0 . 9 6 6}$ & 500 \\
\hline$\underline{16}$ & $\underline{48}$ & $\underline{2}$ & $\underline{3}$ & $\underline{\mathbf{1}}$ & $\underline{266}$ \\
\hline$\underline{20}$ & $\underline{24}$ & $\underline{2}$ & $\underline{1}$ & $\underline{\mathbf{0 . 9 3 3}}$ & $\underline{300}$ \\
\hline$\underline{24}$ & $\underline{27}$ & $\underline{2}$ & $\underline{1}$ & $\underline{\mathbf{0 . 9 4 5}}$ & $\underline{400}$ \\
\hline
\end{tabular}

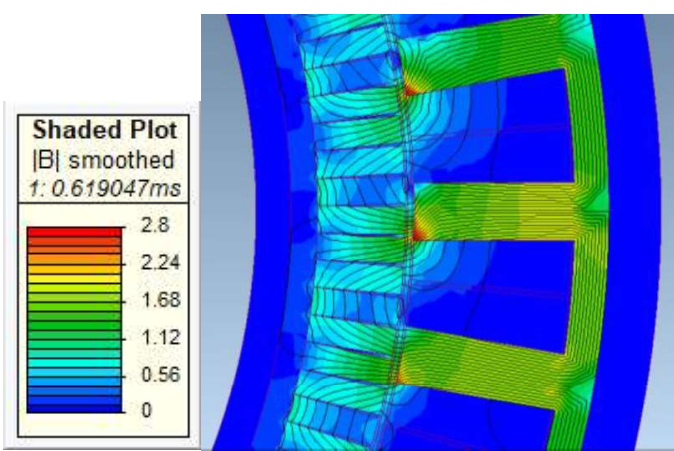

Fig. 3. FE model of the best performing machine after SR and tooth width studies.

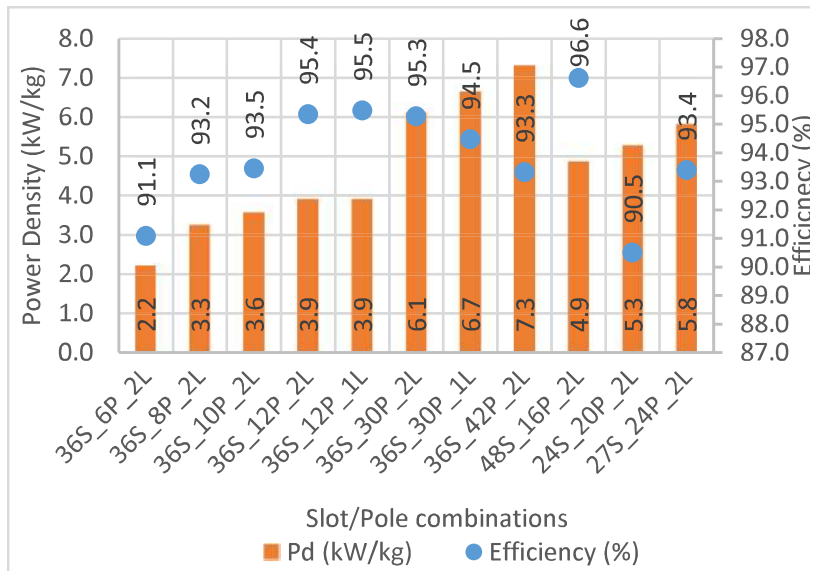

Fig. 4. Performance comparison for the slot/pole combination study.

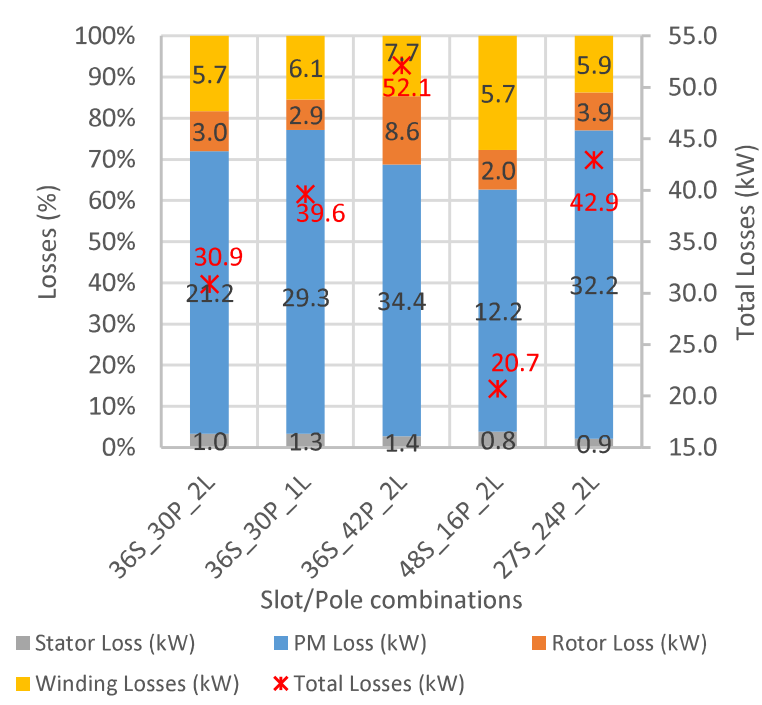

Fig. 5. Losses breakdown for promising slot/pole combinations. 


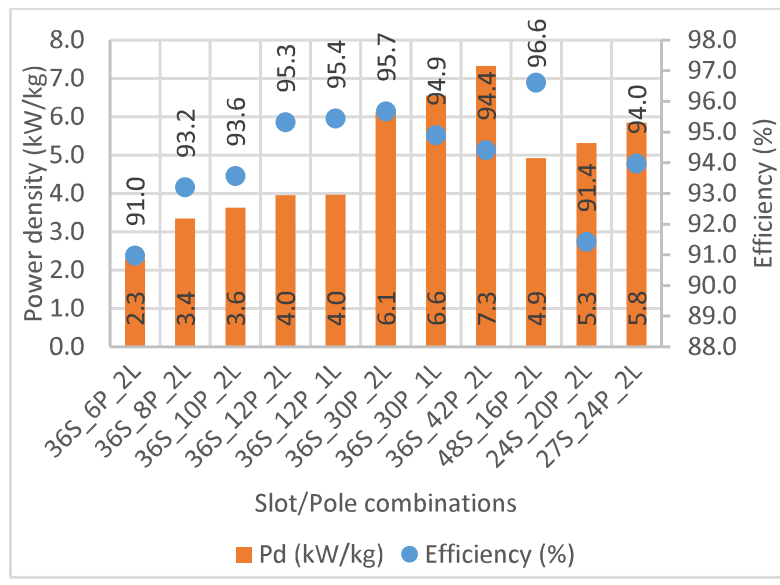

Fig. 6. Performance comparison for the rotor material analysis.

speeds, it experiences higher losses. The rotor material has thus been modified for all the combinations from solid SS-416 to a laminated M350-50A. The rotor losses now are less than $100 \mathrm{~W}$ for all the designs. Figure 6 shows the power density and efficiency for the designs with the new material. A marginal improvement in efficiency could be noticed. Consequently, the $36 \mathrm{~S} / 30 \mathrm{P}$ and the $48 \mathrm{~S} / 16 \mathrm{P}$ emerge as the two promising designs, which are going to be the focus for the next steps.

\section{PM Shape and Orientation}

In order to reduce the PM losses, which so far have been the main contributors to the overall power losses, the PM shape is updated. It is modified from a radial sector with no spaces in between segments, as in Fig. 7.a., to a parallel sector, as in Fig. 7.b. The pole arc angle is also analysed by varying it from 1 to $0.65 \mathrm{pu}$ for the parallel section shape.

The results in Fig. 8 are for the 48S/16P combination for the PM shape analysis. The conclusion is that moving from radial to parallel shape is effective in reducing the PM losses by $\approx 18 \%$. As a result, the efficiency is increased as well by $2.3 \%$ to reach $96.8 \%$. At the same time, the power density is reduced by less than $2 \%$. Also, the torque ripple is reduced when moving to the parallel edge, yet, it increases with a smaller pole arc angle. Additionally, reducing the pole arc angle less than 1 decreases the power density by a noteworthy value. Additionally, this modification has a manufacturing costbenefit. Accordingly, the selected topology from this point onward features a parallel segment with a 1 pu pole arc angle. However, the PM losses are still significant (i.e. higher than 10 $\mathrm{kW}$ ), thus, the further reduction would be achieved through the PM axial segmentation, as discussed in the next sub-section.

\section{E. PM Axial Segmentation}

The PMs have been segmented axially to further reduce the losses. Ideally, 3D FEM should be used for an exact modelling of PM axial segmentation, but this is a rather time and computationally consuming procedure. Therefore, a factor $F_{P M}$ is used as in [20] to emulate the inherent $3 \mathrm{D}$ effects of the axial segmentation in a $2 \mathrm{D}$ FE simulation model. The aforementioned factor is defined as in (1), where ' $\mathrm{l}$ ' is the axial segment length, and ' $w$ ' is the width in the circumference direction per segment. As indicated by (1) and illustrated by Fig. 9, for the same air gap diameter, the axial segmentation is more effective for the 16 poles topology since the width of the $\mathrm{PM}$ segments is bigger than the 30 poles one.

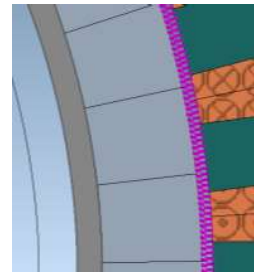

(a)

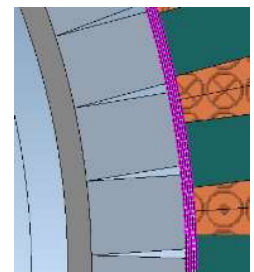

(b)

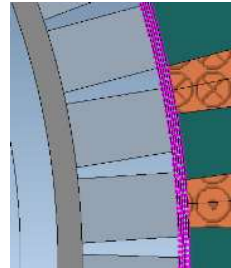

(c)
Fig. 7. PM a) Radial Sector, b) Parallel Section with 1 pu angle, c) Parallel Section with 0.75 pu angle.

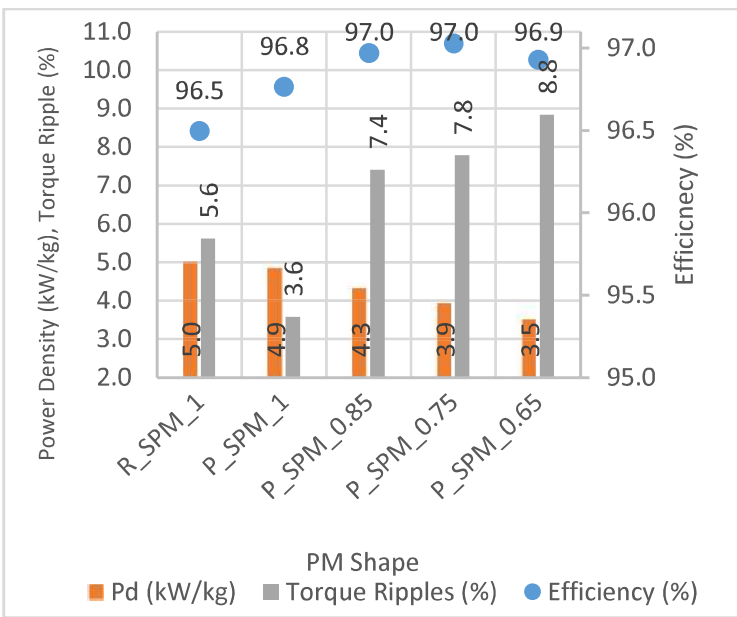

(a)

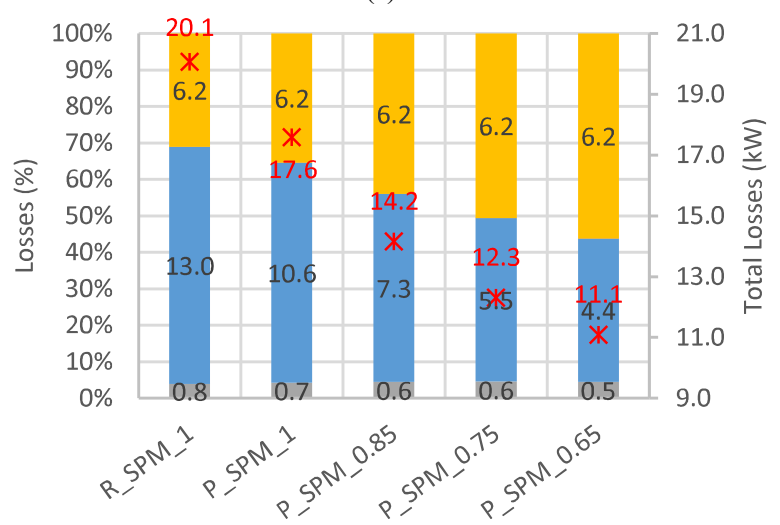

PM Shape

Stator Loss (kW) घ $\quad$ PM Loss (kW) Rotor Loss (kW)

Winding Losses $(\mathrm{kW}) *$ Total Losses $(\mathrm{kW})$

(b)

Fig. 8. Performance comparison for PM shape study.

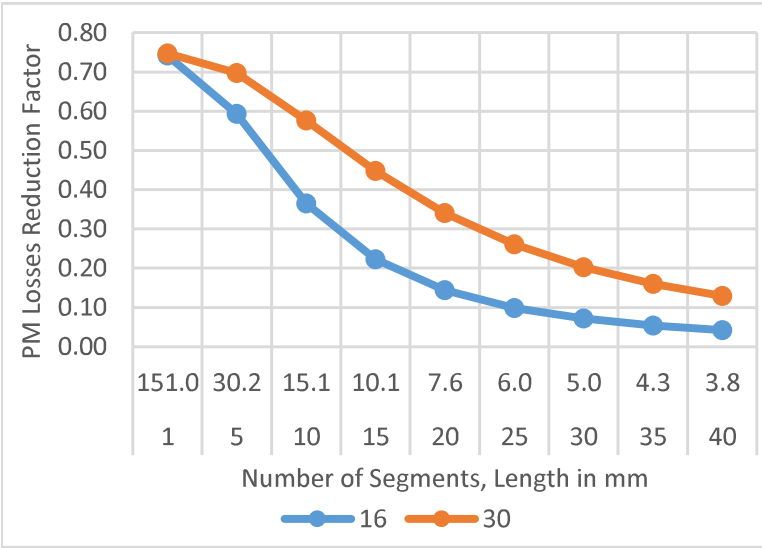

Fig. 9. Axial Segmentation Factor for 16 Poles vs 30 Poles. 


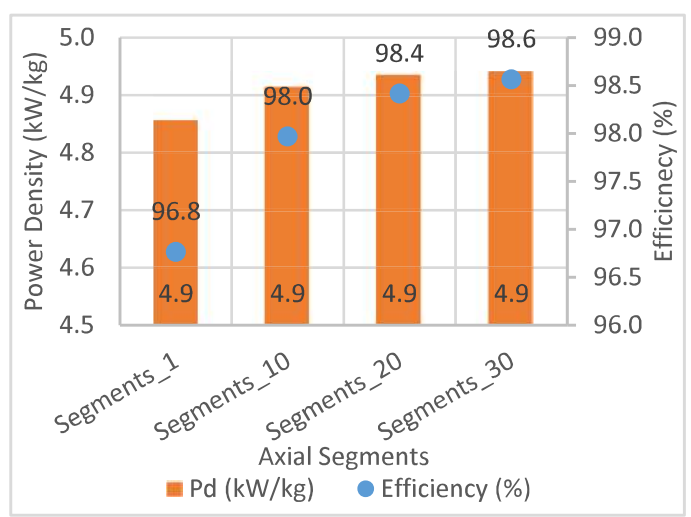

(a)

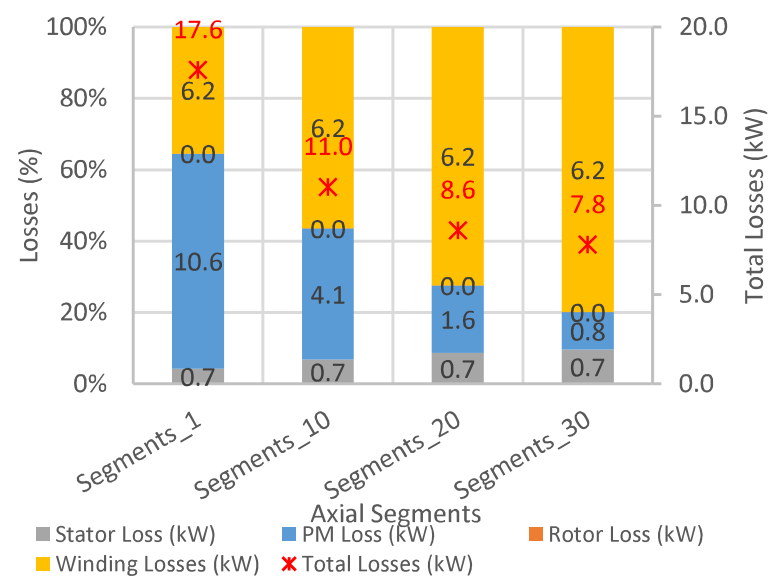

(b)

Fig. 10. PM axial segmentation effect for the 48S/16P, a) Power density and efficiency, b) Losses breakdown.

$$
F_{p m}=\frac{3}{4} \frac{l^{2}}{l^{2}+w^{2}}
$$

In Fig. 10, the effect of axial segmentation on the $48 \mathrm{~S} / 16 \mathrm{P}$ is shown as a case study. The results are generated by adjusting the PM electric resistivity by the same factor from (1). Thus, bearing in mind the thermal limit as well, having 20 segments for the 48S/16P produces PM losses within a thermally accepted range. For the $36 \mathrm{~S} / 30 \mathrm{P}$ design, it might be required to go up to 40 segments to reach a reasonable range. Nevertheless, this increased number of segments indicates higher manufacturing and assembly costs.

\section{F. Multi-Three Phase Groups Windings}

Multi-three phase groups are suggested to further improve the motor performance. Increasing the number of three-phase sets means higher reliability and fault tolerance capability, as well as reducing the absolute current per phase [12]. Hence, 4three-phase winding sets were modelled for the $48 \mathrm{~S} / 16 \mathrm{P}$. The $36 \mathrm{~S} / 30 \mathrm{P}$ combination is also simulated with two 3-phase groups and four 3-phase groups. All the models have axially segmented PMs as indicated in Table IV. The $36 \mathrm{~S} / 30 \mathrm{P}$ required more segments to maintain the PM losses at a low value.

From this analysis, it is evident that the $36 \mathrm{~S} / 30 \mathrm{P}$ is the best design in terms of power density. Yet, the PM losses, even when using 40 segments, are still rather high and can result in high PM temperatures. The power density for the $36 \mathrm{~S} / 30 \mathrm{P}$ with four winding groups looks very promising at $6.9 \mathrm{~kW} / \mathrm{kg}$, i.e. $38 \%$ higher than the target of $5 \mathrm{~kW} / \mathrm{kg}$. Consequently, the selected motor features 36 slots, 30 poles with 4 three-phase winding groups.
TABLE IV

MUlTi-THREE-PHASE GROUPS STUDY

\begin{tabular}{|c|c|c|c|}
\hline & $\mathbf{4 8 S - 1 6 P}$ & $\mathbf{3 6 S - 3 0 P - A}$ & $\mathbf{3 6 S - 3 0 P - B}$ \\
\hline Average Torque (kNm) & 2.9 & 2.7 & $\mathbf{3 . 4}$ \\
\hline Torque Ripple (\%) & 6.5 & $\mathbf{1 . 3}$ & 0.5 \\
\hline Output Power (kW) & 614.6 & 571.4 & $\mathbf{7 1 2 . 8}$ \\
\hline Power Density (kW/kg) & 5.58 & 5.51 & $\mathbf{6 . 9}$ \\
\hline Stator Losses (kW) & $\mathbf{0 . 8}$ & 1.1 & 1.3 \\
\hline PM Losses (kW) & $\mathbf{1 . 4}$ & 3.3 & 3.9 \\
\hline Cu Losses (kW) & 7.2 & $\mathbf{4 . 7}$ & 6.7 \\
\hline Efficiency (\%) & $\mathbf{9 8 . 4}$ & $\mathbf{9 8 . 4}$ & $\mathbf{9 8 . 3}$ \\
\hline I_Ph_max (I) & $\mathbf{3 5 0}$ & 620 & 500 \\
\hline Number of Turns & 6 & 4 & 7 \\
\hline Number of 3- $\boldsymbol{\Phi}$ Groups & 4 & $\mathbf{2}$ & 4 \\
\hline Number PM segments & $\mathbf{2 5}$ & 40 & 40 \\
\hline $\begin{array}{c}\text { PM segment length } \\
\text { (mm) }\end{array}$ & $\mathbf{6}$ & 3.8 & 3.8 \\
\hline
\end{tabular}

TABLE V

COOLING SYSTEM MAIN PARAMETERS

\begin{tabular}{|c|c|}
\hline Parameter & Value \\
\hline Water jacket height (mm) & 4 \\
\hline $\begin{array}{c}\text { Water jacket to housing } \\
\text { (mm) }\end{array}$ & 3 \\
\hline Flow rate (l/min) & 10 \\
\hline Pressure drop (bar) & 1.72 \\
\hline Cooling parallel paths & 1 \\
\hline Cooling fluid & EGW50/50 \\
\hline Number of 3-phase groups & 4 \\
\hline Number of PM segments & 30 \\
\hline PM segment length (mm) & 5 \\
\hline
\end{tabular}

\section{THERMAL MANAGEMENT AND FINAL DESIGN}

So far, the thermal performance has not been discussed in detail and the design process described in Section III assumed a liquid cooling water jacket. In this section, the design of the thermal management system is given in more detail. Then, the final design of the motor is presented along with the overall performance indicators of the ProMo.

\section{A. Thermal Management}

The dominant losses now are the winding Joule losses, as well as a relatively high PM loss. The AC winding losses have been assumed to be zero throughout this study, i.e. skin and proximity effects have been neglected. Considering the above, an appropriate cooling for the stator windings and for the PMs is required. Several different cooling systems have been considered for the motor such as axial cooling jacket, spiral cooling jacket, direct winding cooling, stator and rotor ducts. Finally, a spiral liquid ethylene glycol water (EGW) jacket is employed for the motor stator housing considering its high thermal properties. The main parameters of this cooling spiral jacket are listed Table V. The total pressure drop is less than 2 bar at a flow rate of $10 \mathrm{l} / \mathrm{min}$, the spiral cooling ducts have a width of $13 \mathrm{~mm}$ and a radial thickness of $4 \mathrm{~mm}$. Additionally, a total of 36 axial cooling ducts in the endcaps as indicated in Fig. 11 are implemented to allow airflow through the air gap and rotor. These axial holes in the housing endcaps are of $40 \mathrm{~mm}$ in diameter each.

The results and performance are conducted through MotorCAD thermal solver. The temperatures of different motor parts at steady-state conditions, rotating at $2000 \mathrm{rpm}$ and supplied by a 465 A peak phase current, are summarized in Table VI.

Assuming a winding insulation class of ' $180{ }^{\circ} \mathrm{C}$ ' or higher, the winding temperature is within the limits. The temperature 
TABLE VI

Motor Parts Temperatures at Steady State

\begin{tabular}{|c|c|}
\hline Parameter & Temp. $\left({ }^{\circ} \mathbf{C}\right)$ \\
\hline Ambient & 40 \\
\hline Active winding (maximum) & 178 \\
\hline Active winding (Average) & 145 \\
\hline Magnet & 108 \\
\hline Stator laminations & 76 \\
\hline Rotor laminations & 97 \\
\hline Shaft & 100 \\
\hline Cooling fluid (inlet/outlet) & $40 / 48.4$ \\
\hline
\end{tabular}

TABLE VII

FINAL MACHINE PERFORMANCE INDICATORS

\begin{tabular}{|c|c|}
\hline Parameter & Value \\
\hline Average torque (Nm) & 3577 \\
\hline Torque ripple (\%) & 0.4 \\
\hline Output power (kW) & 749 \\
\hline Power density (kW/kg) & 7.49 \\
\hline Efficiency (\%) & 98.7 \\
\hline Peak phase current (A) & 465 \\
\hline Peak current density & 10.7 \\
\hline (A/mm2) & 7 \\
\hline Number of turns per coil & 2200 \\
\hline Stator losses (W) & 1593 \\
\hline PM losses (W) & 6300 \\
\hline Cu losses (W) & 4 \\
\hline Number of 3-phase groups & 30 \\
\hline Number of PM segments & 5 \\
\hline PM segment length (mm)
\end{tabular}

of the PMs is less than $110{ }^{\circ} \mathrm{C}$. The PMs are SmCo type, which typically has higher thermal tolerance and can withstand temperature up to $350^{\circ} \mathrm{C}$

\section{B. Final Design Discussion}

Further optimisations to the stator have been implemented to fully utilize the material potential. Thus, the final design after these optimizations and sensitivity studies is described as an inner rotor, surface mounted, five-stage Halbach array, with 4 three-phase, concentrated winding. The finalised ProMo has a very competitive power density of $7.5 \mathrm{~kW} / \mathrm{kg}$ and efficiency of $98.7 \%$ for a steady-state operation at $2000 \mathrm{rpm}$ rated speed. The electromagnetic performance, as well as the loss breakdown, are listed in Table VII. The average continuous torque is slightly higher than $3.5 \mathrm{kNm}$, as shown in Fig. 12.b, whereas the torque ripple is only $0.4 \%$ without PMs or stator skewing. The output power at continuous operation is $\approx 750 \mathrm{~kW}$, thus it could be fitted for commercial 8-12 passengers aircraft such as Cessna Caravan [15]. The winding arrangement is a concentrated type, subsequently reducing the end winding length and associated losses and boosting the motor's efficiency. Incorporating a quadruple three-phase winding will improve the motor overall reliability, operation as well as de-rating capability in the event of partial winding failure [21]. Consequently, the proposed design development of this middle-mile propulsion motor proved to be very effective when compared to commercial motors for the same application as listed in Table VIII.

\section{CONCLUSIONS}

This paper presented the design procedure adopted for a high-power density permanent magnet synchronous motor for direct-drive middle-mile commercial aircraft applications. A number of design parameters have been optimally selected,
TABLE VIII

PRoMo PERFORMANCE COMPARISON TO OTHER MACHINES

\begin{tabular}{|c|c|c|c|c|}
\hline Parameter & $\begin{array}{c}\text { Proposed } \\
\text { ProMo }\end{array}$ & $\begin{array}{c}\text { Magni500 } \\
{[\mathbf{1 5}]}\end{array}$ & $\begin{array}{c}\text { Magni250 } \\
{[\mathbf{1 5}]}\end{array}$ & $\begin{array}{c}\text { Siemens } \\
{[\mathbf{6}]}\end{array}$ \\
\hline Power (kW) & 750 & 560 & 280 & 260 \\
\hline Torque (Nm) & 3577 & 2814 & 1407 & 993 \\
\hline Rated speed (rpm) & 2000 & 1900 & 1900 & 2500 \\
\hline DC bus voltage (V) & 540 & 540 & 540 & 580 \\
\hline Efficiency (\%) & 98.7 & 93.8 & 93.8 & 95 \\
\hline Pd (kW/kg) & 7.49 & 4.67 & 4.66 & 5.2 \\
\hline Weight (kg) & 100 & 120 & 60 & 50 \\
\hline
\end{tabular}
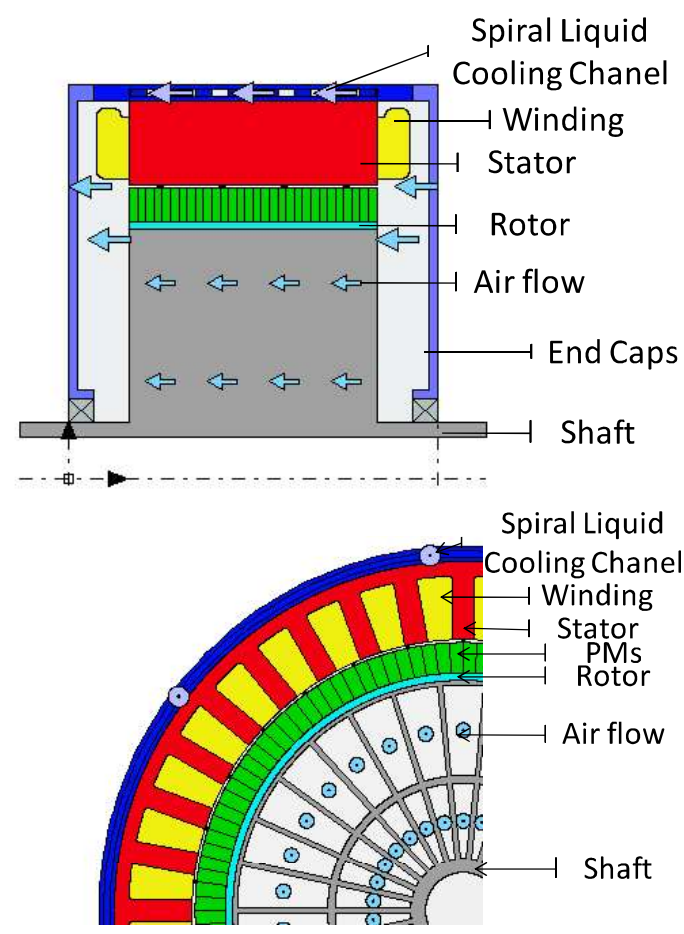

Fig. 11. Cooling System Configuration

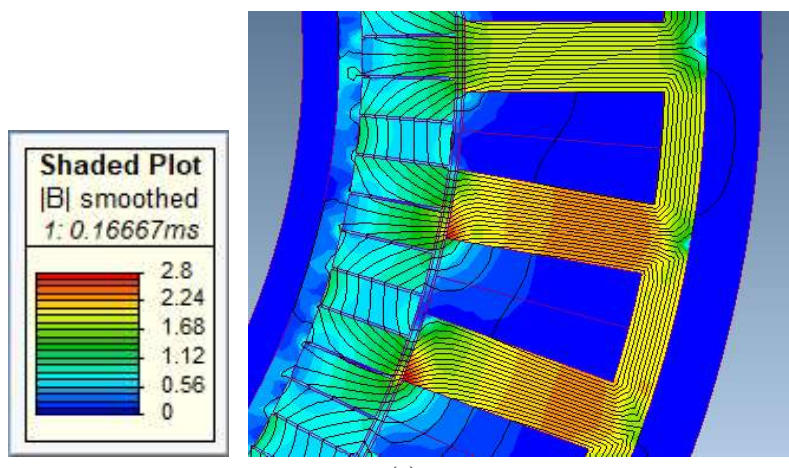

(a)

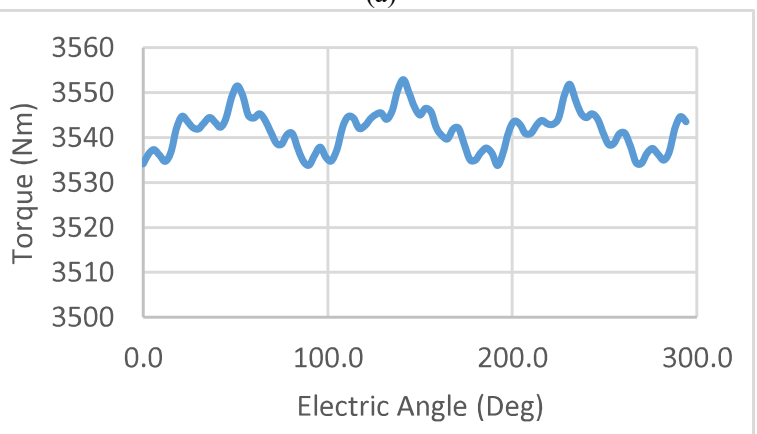

(b)

Fig. 12. Final design: a) flux-lines and flux density map, b) output full-load torque 
such as air gap diameter slot/pole combination, number of axial PMs segments, number of three-phase sets, etc. A detailed thermal analysis is also performed for a suitable choice of the machine cooling. The design process, started from a reference motor used for short duty cycle operation, led to the achievement of the challenging requirements initially assumed. In particular, the final design features an efficiency of $98.6 \%$, a power density of $7.49 \mathrm{~kW} / \mathrm{kg}$ and an output continuous power of $750 \mathrm{~kW}$.

Future developments of these studies will involve further design refinements of the proposed propulsion motor as well as a full-scale prototype will be built and tested for validation.

\section{REFERENCES}

[1] X. Roboam, B. Sareni, and A. De Andrade, "More Electricity in the Air," Ind. Electron. Mag. IEEE, vol. 6, no. 4, pp. 6-17, 2012.

[2] W. Cao, B. C. Mecrow, G. J. Atkinson, J. W. Bennett, and D. J. Atkinson, "Overview of electric motor technologies used for more electric aircraft (MEA)," IEEE Trans. Ind. Electron., vol. 59, no. 9, pp. 3523-3531, 2012.

[3] M. Lukic, P. Giangrande, A. Hebala, S. Nuzzo, and M. Galea, "Review, Challenges and Future Developments of Electric Taxiing Systems," IEEE Trans. Transp. Electrif., vol. PP, no. c, p. 1, 2019.

[4] M. Lukic et al., "State of the Art of Electric Taxiing Systems," in 2018 International Conference on Electrical Systems for Aircraft, Railway, Ship Propulsion and Road Vehicles \& International Transportation Electrification Conference (ESARS-ITEC), 2018.

[5] J. Hoelzen et al., "Conceptual design of operation strategies for hybrid electric aircraft," Energies, vol. 11, no. 1, pp. 1-26, 2018.

[6] A. El-Refaie and M. Osama, "High specific power electrical machines: A system perspective," 2017 20th Int. Conf. Electr. Mach. Syst. ICEMS 2017, vol. 3, no. 1, pp. 88-93, 2017.

[7] M. Galea, Z. Xu, C. Tighe, T. Hamiti, C. Gerada, and S. Pickering, "Development of an aircraft wheel actuator for green taxiing," Proc. - 2014 Int. Conf. Electr. Mach. ICEM 2014, pp. 2492-2498, 2014.

[8] X. Zhang and K. S. Haran, "High-specific-power electric machines for electrified transportation applications-technology options," ECCE 2016 - IEEE Energy Convers. Congr. Expo. Proc., pp. 1-8,
2016

[9] S. Downing, "6 electric aviation companies to watch," 2019 [Online]. Available: https://www.greenbiz.com/article/6-electricaviation-companies-watch. [Accessed: 30-Oct-2019].

[10] M. Henke et al., "Challenges and opportunities of very light highperformance electric drives for aviation," Energies, vol. 11, no. 2, 2018.

[11] "Zunum Aero." [Online]. Available: https://zunum.aero/. [Accessed: 30-Oct-2019].

[12] "A giant leap towards zero-emission flight." [Online]. Available: https://www.airbus.com/innovation/future-technology/electricflight/e-fan-x.html. [Accessed: 30-Oct-2019].

[13] "Cristian Anghel, 'High-efficiency and high-power-density generator rated for 1MW', Electric \& Hybrid Aerospace Technology Symposium, Nov. 2015, Bremen, Germany."

[14] D. Golovanov, M. Galea, and C. Gerada, "High specific torque motor for propulsion system of aircraft," 2016 Int. Conf. Electr. Syst. Aircraft, Railw. Sh. Propuls. Road Veh. Int. Transp. Electrif. Conf. ESARS-ITEC 2016, 2017.

[15] "Magnix Aero." [Online]. Available: https://www.magnix.aero/. [Accessed: 30-Oct-2019].

[16] M. Rosu, M. Popescu, and D. M. Ionel, "Basics of Electrical Machines Design and Manufacturing Tolerances," in Multiphysics Simulation by Design for Electrical Machines, Power Electronics, and Drives, John Wiley \& Sons, Ltd, 2017, pp. 1-43.

[17] M. Galea et al., "Design aspects of a high torque density machine for an aerospace traction application," in 2014 17th International Conference on Electrical Machines and Systems, ICEMS 2014, 2015, pp. 2773-2778

[18] T. Jokinen and V. Hrabovcova, Design of Rotating Electrical Machines, Second Ed. John Wiley \& Sons, 2008.

[19] W. A. M. Ghoneim, A. Hebala, and H. A. Ashour, "Sensitivity Analysis of Parameters Affecting the Performance of Radial Flux Low-Speed PMSG," in Proceedings - 2018 23rd International Conference on Electrical Machines, ICEM 2018, 2018, pp. 968974.

[20] S. Ruoho, T. Santa-nokki, J. Kolehmainen, and A. Arkkio, "Modeling Magnet Length In 2-D Finite-Element Analysis of Electric Machines," IEEE Trans. Magn., vol. 45, no. 8, pp. 31143120, 2009.

[21] M. Villani, M. Tursini, G. Fabri, and L. Castellini, "Multi-phase fault tolerant drives for aircraft applications," Int. Conf. Electr. Syst. Aircraft, Railw. Sh. Propulsion, ESARS 2010, 2010. 